\title{
Nova espécie de Nesothamnus Linnavuori (Homoptera, Cicadellidae, Deltocephalinae, Scaphytopiini) ${ }^{1}$
}

\author{
Keti Maria Rocha Zanol ${ }^{2}$
}

\begin{abstract}
A new species of Nesothamnus Linnavuori (Homoptera, Cicadellidae, Deltocephalinae, Scaphytopiini). Nesothamnus amazonicus sp. n., from Brazil, is described and illustrated.

KEY WORDS. Homoptera, Cicadellidae, Deltocephalinae, Scaphytopiini, Nesothamnus
\end{abstract}

LINNAVUORI (1959) descreveu o gênero e espécie Nesothamnus sanguineus, com base num exemplar fêmea proveniente de Madre de Dios, Peru. DELong (1982) descreveu o macho desta espécie porém indicou o pseudóstilo como sendo o edeago. WEBB \& GoDOy (1993) perceberam o engano e redescreveram a genitália do macho. No presente trabalho descreve-se uma nova espécie do Amazonas, Brasil, Nesothamnus amazonicus $\mathbf{s p .} \mathbf{n}$.

O gênero Nesothamnus Linnavuori, 1959 caracteriza-se por apresentar a cabeça mais estreita que o pronoto; face alongada; genas com as margens retas e visíveis de cima; sutura transclipeal obscura. Tégminas com apêndice desenvolvido, duas células anteapicais, primeira e segunda células apicais grandes; veias Anais fundidas próximo à veia extranumerária entre $1 \mathrm{~A}$ e a sutura claval. Espinulação dos fêmures posteriores $2+2+1$ e das tíbias anteriores 1+4. Edeago simétrico, não articulado com o conetivo; conetivo com os braços bem separados; pseudóstilo articulado com o conetivo. Sétimo esternito da fêmea de forma mais ou menos triangular.

O material estudado está depositado nas seguintes instituições: Coleção de Entomologia Pe J.S. Moure, Curitiba, Paraná (DZUP), Instituto Nacional de Pesquisa da Amazônia, Manaus, Amazonas (INPA) e Universidade Federal do Amazonas, Manaus, Amazonas (UFAM).

\section{Nesothamnus amazonicus sp.n.}

Figs 1-8

Holótipo macho. Coroa castanho-dourada com três manchas triangulares, na margem anterior, marfins; margem anterior, entre os ocelos, preta. Face avermelhada. Lora, parte das genas e uma mancha ovalada, no frontoclipeo, amarelas.

Pronoto castanho-avermelhado; margens látero-posteriores vermelhas; margens látero-anteriores, marfins. Escutelo castanho-avermelhado; triângulos basais castanhos; ápice marfim. Tégminas castanho-avermelhadas; margem escutelar mar-

1) Contribuição número 1212 do Departamento de Zoologia, Universidade Federal do Paraná.

2) Departamento de Zoologia, Universidade Federal do Paraná. Caixa Postal 19020, 81531-990 Curitiba, Paraná, Brasil. Bolsista do CNPq. 
fïm; margem anal, venação e margem costal vermelhas; área costal preta; primeira célula discal preta em quase toda sua extensão; quinta célula apical vermelha com uma estreita mancha preta; célula anteapical externa margeada de preto na base e junto à primeira célula apical; célula anteapical central com uma mancha preta na base; células apicais com uma mancha arredondada preta, na base
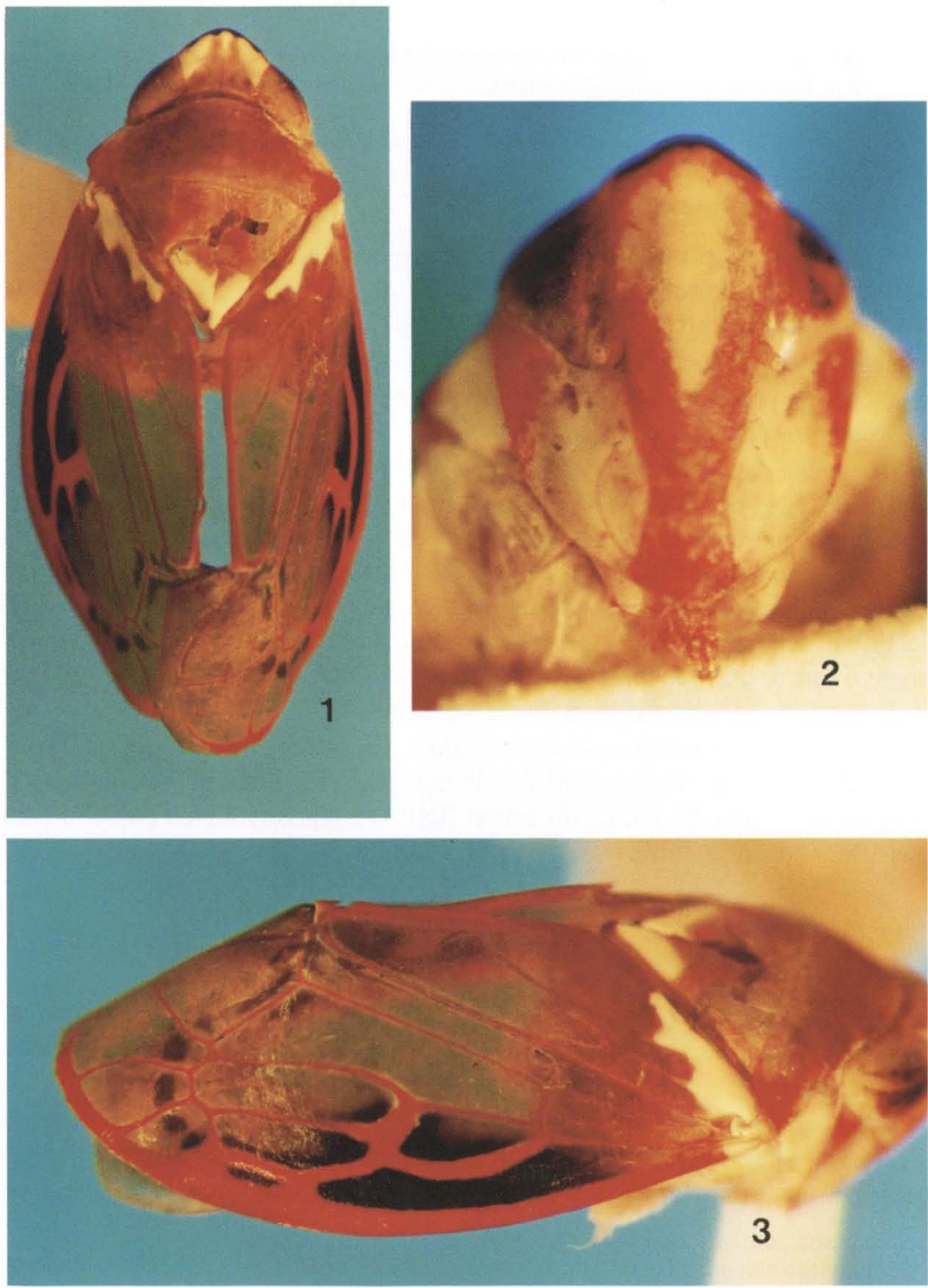

Figs 1-3. Nesothamnus amazonicus sp. n., holótipo. (1) Vista dorsal; (2) face; (3) tégmina, vista lateral.

Revta bras. Zool. 18 (2): $391-394,2001$ 
Pigóforo sem apêndices. Valva genital elíptica. Placas subgenitais triangulares; macrocerdas unisseriadas. Estilos digitiformes. Edeago, em vista lateral, com um pequeno processo apical, esclerotinizado, na superfície dorsal. Pseudóstilo lanceolado, tão longo quanto o comprimento do pigóforo; superfície com inúmeros pêlos, na metade apical.

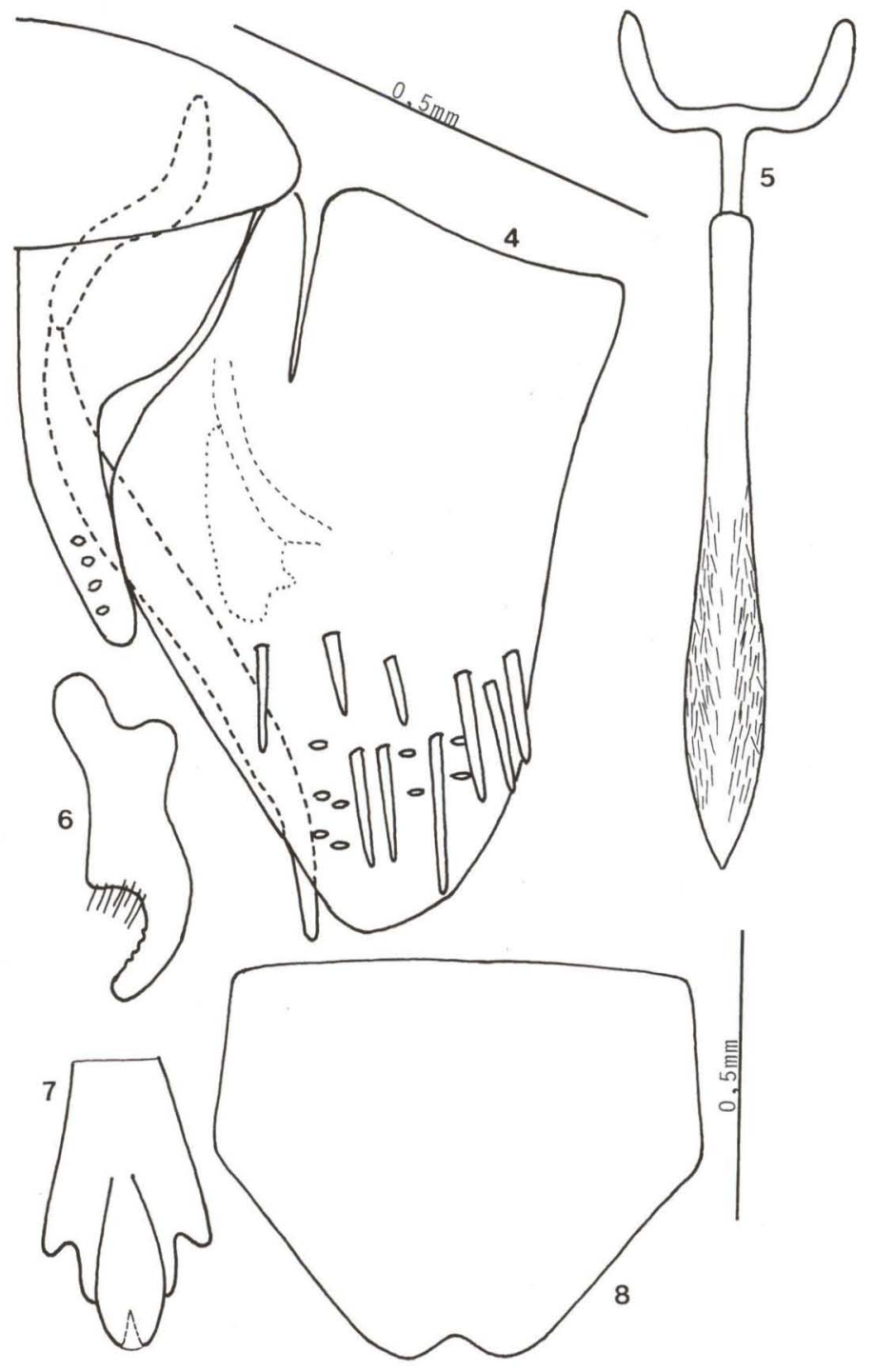

Figs 4-8. Nesothamnus amazonicus sp. n., holótipo. (4) Vista lateral de genitália: placa subgenital, conetivo, pseudóstilo, edeago e pigóforo; (5) conetivo e pseudóstilo, vista ventral; (6) estilo; (7) edeago, vista ventral; (8) sétimo esternito da fêmea. 
Fêmea. Semelhante ao macho porém mais avermelhada. Coroa avermelhada. Pronoto com duas faixas vermelhas, longitudinais e medianas unidas às manchas látero-posteriores, por uma faixa transversa, junto aos olhos, vermelhas. Escutelo com triângulos basais margeados de vermelho. Sétimo esternito com a margem posterior oblíqua, sinuosa e com uma pequena fenda mediana.

Comprimento total (em milímetros). Macho: 5,60; fềmea: 6,00.

Material examinado. Holótipo macho, BRAsil, Amazonas: Tabatinga, 1419.VII.1991, C. Carvalho leg. (DZUP). Parátipos. Ibidem: Coari, (Rio Urucu, Angelio, 53'33'S 65'14'48'W), 23.XI-02.XII.1992, P.F. Bührnhein \& N.O. Aguiar leg., 1 fêmea (UFAM); Rondônia: Nova Mamoré, (Parque Estadual Guajará-Mirim, 10¹9'26"S 643'88"W, Rio Formoso), 20-27.X.1995, Vidal e Aquino leg., 1 macho (DZUP), Cacaulândia, 140 m, 13-31.XII.1997, V.O. Becker leg., 1 fêmea (DZUP); Acre: 11 km NE de Rio Branco, 06-10.V.1981, Jorge Arias leg. , 4 machos (INPA), Cruzeiro do Sul, 17.V.1981, Jorge Arias leg., 1 macho (DZUP).

\section{REFERÊNCIAS BIBLIOGRÁFICAS}

DELong, D.M. 1982. New and little known south american Deltocephalinae (Homoptera: Cicadellidae) with description of a new genus, Sincholata. Brenesia 19/20: 477-485.

LinNAVUORI, R. 1959. Revision of the Neotropical Deltocephalinae and some related subfamilies (Homoptera). Ann. Zool. Soc. Vanamo 20 (1): 1-370.

WEBB, M.D. \& C. Godoy. 1993. Review of the leafhopper tribe Scaphytopiini (Homoptera: Cicadellidae: Deltocephalinae) with a key to genera. Jour. Nat. Hist. 27: 423-427.

Recebido em 29.VI.2000; aceito em 07.V.2001. 